\title{
LA INDUSTRIA GALLETERA EN ESPAÑA
}

\author{
POR \\ FRANCISCO FEO PARRONDO
}

\section{Introducción}

Pese a representar un 15\% del empleo industrial español, un $20 \%$ de sus ventas y a que un $80 \%$ de los alimentos consumidos por los españoles han sufrido transformaciones agroindustriales, durante la década de los noventa, se ha constatado numerosas veces el déficit de estudios geográficos sobre el sector agroindustrial (García Ramón, 1992, pp. 26; Feo Parrondo, 1991, pp. 21-22; 1997a, pp. 111 y 1997b, pp. 565). En este último estudio señalábamos, como principales razones de esta marginación, la importancia reciente de algunos sectores agroindustriales (por ejemplo, el galletero no tiene en España un peso significativo hasta bien avanzados los años cincuenta) y la escasez de datos fiables, dada la reticencia de las empresas a facilitarlos ${ }^{1}$.

En este trabajo tratamos de subsanar parcialmente estos déficits analizando el sector galletero en España en el que, a las dificultades anteriormente apuntadas, hay que añadir otras dos: los diferentes criterios estadísticos de cada fuente y la propia definición de galletas. La primera se debe a que unas veces se ofrecen datos ex-

1 Teniendo en cuenta esta situación, deseo agradecer la documentación facilitada sobre el Grupo Siro por su presidente don Juan Manuel González Serna.

Francisco Feo Parrondo: Departamento de Geografía de la Universidad Autónoma de Madrid.

Estudios Geográficos

Tomo LXI, 2000, n. ${ }^{\circ} 239$, abril-junio 
clusivamente sobre el sector galletero (ALIMARKET), otras veces se incluyen datos cojuntos de «bollería, pasteles y galletas» (MAPA hasta 1997), e incluso de conjuntos más amplios como «pan, galletas y productos de panadería y pastelería» (INE, 1997), sin olvidarnos de que las empresas suelen dar cifras de sus ventas (cuando las dan) sin desagregarlas por productos. Todo ello hace que cualquier cifra haya que interpretarla con bastante precaución. Si nos atenemos a la Encuesta Industrial de empresas, elaborada por el INE, el sector de pan, bollería y galletas acaparaba en los años ochenta aproximadamente la mitad de las agroindustrias españolas: 22.963 de las 49.019 existentes en 1980, 22.444 de las 41.589 en 1985 y 22.952 de las 41.589 agroindustrias españolas en 1989 (Bustos Gisbert, 1994, pp. 235). El porcentaje del sector iba en aumento por ser las más reducidas en número de empleos, valor añadido, etc., debido a la inclusión de muchas pequeñas panaderías. En 1989, el sector acaparaba el 55,19\% de las empresas agroindustriales pero sólo el 18,28\% del empleo agroalimentario y el 14,34\% de su Valor Añadido Bruto (Bustos Gisbert, 1994, pp. 231).

Según esta misma fuente, en 1995 había unas 13.749 empresas en el sector de pan, galletas y pastelería, de las cuales 12.999 (el 94,5\%) tenía menos de veinte trabajadores (la media era de 7,77 ). Ocupaban a 106.884 personas y generaban unos ingresos de 700.884 millones de pesetas (INE, 1997, pp. 55). Estas cifras son muy elevadas por la importancia del pan en las mismas y se reducen notablemente en otras fuentes. Así, por ejemplo, la Junta de Castilla y León, región que es la de mayor producción de galletas en España, sólo incluía en 1990 un total de 43 empresas de bollería, pasteles y galletas y otras cuatro exclusivamente productoras de galletas (Junta..., 1990, pp. 261-262). Pese a ser una fuente «oficial» se olvida de fábricas existentes en Lerma, Miranda de Ebro, Burgos, Venta de Baños, Toro, etc., pertenecientes a industrias que estaban entre las 20-30 del sector en España. Tampoco incluso «otros productos que han ganado su merecida cuota de mercado, como los "Nicanores" de Boñar, las "Mantecadas" y "Hojaldres" de Astorga, los "Imperiales» de La Bañeza y los "Lazos de San Guillermo" de Cistierna, por citar algunos de los más representativos y conocidos fuera de la provincia» (Maya Frades, 1996, pp. 83). Estos olvidos, corregidos en posteriores anuarios de la Junta, son muy difíciles de justificar en casos como los de «las mantecadas de As- 
torga (que) gozan de gran tradición y son sobradamente conocidas por los consumidores, por lo que los productores han empezado los trámites encaminados a conseguir el marchamo de la calidad» (Maya Frades, 1996, pp. 98). Parte de estas deficiencias pueden proceder de la dificultad de delimitar la producción de galletas respecto de la de bollería y pastelería.

\section{Definición de «galletas»}

Antiguamente el concepto galleta definía al «pan de forma plana y completamente desecado, de larga conservación, destinada al aprovisionamiento de buques y ejércitos en campaña. Hoy se ha extendido esta denominación a una larga serie de productos de variadas formas y gustos y puede decirse que cada época, país y aun cada región tienen sus propios tipos» (AA.VV., 1990, pp. 44).

La Real Academia Española aún conserva entre sus definiciones de galleta la de «pan sin levadura para los barcos» aunque la primera que ofrece es: «pasta compuesta de harina, azúcar y a veces huevo, manteca o confituras diversas, que, dividida en trozos pequeños y moldeados o modelados en forma varia, se cuecen al horno» (Real Academia Española, 1992, t. I, pp. 1016).

El INC (Instituto Nacional de Consumo) define muy poco específicamente las galletas como «productos alimenticios elaborados fundamentalmente por una mezcla de harina, grasas comestibles y agua, adicionada o no de azúcares y otros productos alimenticios o alimentarios (aditivos, aromas, condimentos, especias, etc.) sometida a proceso de amasado y posterior tratamiento térmico, dando lugar a un producto de presentación muy variada, caracterizado por su bajo contenido en agua» (INC, 1982, pp. 3-4). La razón de esta escasa precisión tal vez sea la enorme variedad de productos que se incluyen como galletas: marías tostadas y troqueladas, cracker y de aperitivo, barquillos con y sin relleno, bizcochos secos y blandos, sandwichs, pastas blandas y duras, bañadas en aceite vegetal, recubiertas de chocolate, surtidos y otras (INC, 1982, pp. 4-6). Una década antes, Gianola ofrecía casi quinientas fórmulas para otras tantas variedades, incluyendo el contenido de cada producto y los aspectos técnicos de su modo de elaboración (Gianola, 1973). 


\section{Orígenes y evolución}

El término galleta, de origen francés, reemplaza al castellano bizcocho desde el siglo XVIII en algunas zonas (AA.VV., 1990, pp. 47). Sin embargo, «la industria galletera y la pastelería industrial nacieron en Inglaterra en 1815. Fue la empresa Carr y Cía de Carlisle la que empezó a aplicar el sistema mecánico, y así un desarrollo prodigioso, y llegaron casi a constituir, durante largos años, un verdadero monopolio de los ingleses (...). La fábrica Macfarlane, de Edimburgo, fue fundada en 1817; Huntley y Palmer, en 1826, pero en 1861 se instaló una fábrica en Hamburgo y pocos años después apareció una fábrica en Burdeos (...). El precio módico de la galleta, comparado con los géneros de pastelería fresca, su larga conservación y su buen sabor ayudaron a conquistar el favor del público y su mercado penetró hasta los más humildes pueblos» (Gianola, 1973, pp. 38).

Todos los autores que hacen mención a la evolución de la industria galletera señalan que su expansión se inicia en el siglo XIX cuando pasa de ser un sustitutivo del pan a tener un peso propio y se generaliza su uso entre los mineros de Gales, obreros de las fábricas de Manchester, soldados británicos destacados en Australia, etc., lo que hace que de pequeñas empresas artesanas se pase a otras más mecanizadas y con un proceso de fabricación acorde con la nueva demanda y rentabilidad del producto. La mecanización se inicia en 1817 en Inglaterra, en 1846 en Francia, 1850 en Italia, 1870 en Bélgica y Holanda, 1899 en Suiza, 1911 en Finlandia, etc. (AA.VV., 1990, pp. 122-126). En esta expansión jugó un papel decisivo la galleta «maría», que saca al mercado en 1875 la firma Peek Frean \& Co. Ltd. para celebrar la boda de la Gran Duquesa María de Rusia con el Duque de Edimburgo (AA.VV., 1990, pp. 110) y que con el paso del tiempo se convierte en la de mayor consumo hasta que la diversificación actual ha reducido su importancia relativa en el sector.

La primera guerra mundial hizo aumentar enormemente el consumo de galletas, generalizándose en los ejércitos y posteriormente en el resto de la sociedad en la medida en que su poder adquisitivo aumentaba hasta llegar a un consumo generalizado en todas las capas y niveles sociales de los países desarrollados.

En España, la industria galletera apenas tiene peso hasta 1955 (AA.VV., 1990 , pp. 141) pese a que las primeras factorías surgen a fines del XIX en Palencia, Burgos, Bilbao, Zaragoza y Barcelona de la mano de empren- 
dedores panaderos-pasteleros como Viñas, Olibet, Rius, Fontaneda, Artiach, Loste, Espallargas, Palacios, etc. (AA.VV., 1987, pp. 131). Donde mayor peso van a adquirir es en Castilla-León, continuando la tradición de la industria harinera regional que ya a mediados del siglo xIx acaparaba el $33,40 \%$ de los molinos españoles, el $34,70 \%$ de las fábricas de harina, el $30,90 \%$ del capital del sector, el $24 \%$ de los obreros y el $32,77 \%$ de la producción harinera (Manero, 1983, pp. 22). En las décadas de los cuarenta y cincuenta surgen «Industrias Loste» en Burgos, «Riera-Marsá» en Tordesillas y «Aly» (absorbida en los setenta por «Kraft») en León y las principales fábricas galleteras palentinas (Manero, 1983, pp. 49). Este autor señala la importancia de la industria agroalimentaria en la región: en 1960, representaba el $38,2 \%$ de las ventas, porcentaje que se elevaba al $50,4 \%$ en Palencia, $55,4 \%$ en Ávila y 65,7\% en Zamora (Manero, 1983, p. 72) y a comienzos de los ochenta el mismo autor no duda en afirmar: «en el sector agroalimentario destaquemos, por su firme implantación en el mercado nacional, la personalidad de las fábricas galleteras palentinas ("Fontaneda", "Siro", "Gullón") (Manero, 1983, p. 172). Otros estudios confirman la importancia de alguna de estas empresas. Es el caso de «Fontaneda», que en 1984 era la principal agroindustria palentina con $4.500 \mathrm{mi}-$ llones de pesetas en ventas y en la década anterior había sido de las que más inversiones había realizado en la provincia con el fin de ampliar su planta de Aguilar de Campoo (Herrero Prieto, 1990, pp. 41 y 17).

Desde finales de los años cincuenta, la liberalización del mercado de primeras materias juega un papel decisivo en el despegue del sector galletero español, despegue que se acentúa en los sesenta al aumentar el consumo como consecuencia de la mejora en el nivel de vida por lo que «los industriales galleteros se afanan en la modernización de sus instalaciones, se crean nuevas empresas, y las galletas dejan de tener el carácter de producto selectivo de consumo, para pasar a ser uno de los más populares y básicos alimentos de nuestro país» (AA.VV., 1987, p. 180). Entre 1961 y 1983, casi se cuadruplica la producción, pasando de 49.331 a 192.197 toneladas (AA.VV., 1987, p. 181).

En 1987, operaban en el sector galletero español unas cien empresas que empleaban a unas 4.300 personas y generaban ventas por valor de unos 35.000 millones de pesetas (AA.VV., 1987, p. 132). Existían todo tipo de estructuras empresariales, desde las familiares y locales hasta las grandes como «Fontaneda» $\mathrm{y}$ «Cuétara». El mejor ejemplo de esta disparidad es que las doce mayores controlaban aproximadamente el $80 \%$ 
del mercado. Como consecuencia de esta dicotomía, se estaba produciendo «por parte de los industriales más modestos, una especie de acaparamiento progresivo de la fabricación y venta en determinadas áreas geográficas de los tipos de galleta más sencillos, y de más arraigada demanda, aparte de los productos peculiares que constituyen auténticas especialidades. Por el contrario, y como es pefectamente lógico, son los grandes fabricantes los que profundizan, cada vez más y con especial preferencia, en el sector más sofisticado de la producción galletera, lanzando al mercado nuevos productos, de mayor elaboración, mejor presentación, superior versatilidad de uso y gustos más refinados. Un claro ejemplo de este proceso de especialización productiva, a cargo de la primera línea de industriales galleteros, es que, frente a la muy frecuente fabricación y venta de la tradicional galleta "María", presente en la oferta de la gran mayoría de los elaboradores, son sólo cinco marcas las que, en su conjunto, ocupan nada menos que el $92 \%$ del mercado de galletas tipo "sandwiches" (AA.VV., 1987, pp. 132-133).

En 1990, el número de empresas se había reducido a unas 60 de diferentes tamaños, que empleaban a unos 5.000 trabajadores y generaban ventas por valor de 35.000 millones de pesetas (AA.VV., 1990, pp. 143). En dicho año transformaba 135.000 toneladas de harina, 41.000 de azúcar, 26.000 de materias grasas, 2.400 de leche en polvo, 1.824 de huevos, 624 de chocolate, y cantidades menores de otras materias primas como almendras, avellanas, etc. (AA.VV., 1990, pp. 142).

Estos cambios se aceleran desde mediados de los ochenta para hacer frente a dos amenazas significativas para el sector galletero: la creciente importación de galletas tras la entrada en la Unión Europea y el auge de los cereales en los desayunos. Este último se ve favorecido por la liberalización de las importaciones desde enero de 1987 alcanzando crecimientos de sus ventas del 30\% anual (Labrador, 1987, p. 5). Su consumo crece menos en los años noventa, pero habitualmente supera el 5\% anual, captando cada vez más adeptos en los segmentos infantil y juvenil, lo que garantiza sus posibilidades de expansión futura, buenas por la diversificación de productos y la elevada inversión en publicidad que realizan las multinacionales que controlan el sector: Kellogg acapara el $65 \%$ del mercado español de cereales de desayuno y Nestlé un 12,5\% en 1996 (Escorihuela, 1996, p. 6). Este peso de las multinacionales se traduce en que un $45 \%$ de los cereales consumidos sean de importación. Sólo una empresa española (Pascual), a través de su filial «Cereales Ex- 
pandidos», y dentro de su proceso de diversificación productiva, tiene un cierto peso en el sector con un 7,6\% de la cuota de mercado, en el que cada vez adquieren más peso las marcas blancas.

\section{Situación reciente}

Los problemas de delimitación del sector, anteriormente apuntados, hacen oscilar enormemente las cifras sobre empresas, producción, ventas, empleo, etc., complicaciones que se acentúan por la diversificación productiva de las grandes empresas, cuyas cifras de ventas suelen englobar todos los ingresos sin identificar las cantidades aportadas por cada uno de los sectores productivos: galletas, pastelería industrial, aperitivos, pan, pastas, etc.

A lo largo de los noventas, y especialmente en su primera mitad, crece poco la producción de galletas, superando siempre las 200.000 toneladas anuales, para llegar a un máximo de unas 270.000 toneladas en 1997, de las cuales unas 213.000 se destinaron al mercado interior y 57.000 a la exportación (MAPA, 1998). El incremento en la producción en esta década se ha debido casi exclusivamente al aumento de las exportaciones, sobre el que luego volveremos. Las cifras de producción son, sin embargo, muy superiores según la «Encuesta industrial de productos», ya que llegarían a 371.126 toneladas en 1997 (INE, 1998, pp. 21), lo que puede explicarse por utilizar un concepto de galleta distinto, que incluye rosquillas, polvorones, pastas dulces, etc.

El valor de la producción ha aumentado más gracias a la diversificación de artículos, cada vez más elaborados y variados, superando los 118.000 millones de pesetas en 1997, un 11\% más que en 1996 (MAPA, $1998)^{2}$. Esta diversificación ha sido posible por la concentración empresarial y para hacer frente a la amenaza de las importaciones desde otros países de la Unión Europea, al aumento del consumo y variedades de los cereales de desayuno y artículos de pastelería industrial, aunque en esta última, las magdalenas representan aún el $40 \%$ de las ventas.

Los incrementos del valor de las ventas han sido normalmente mayores que los de beneficios por los gastos crecientes en publicidad

${ }^{2}$ Pese a que la «Encuesta Industrial de productos» cifraba la producción en casi 100.000 toneladas más, las cifras de ventas que ofrece son prácticamente similares a las facilitadas por el MAPA: 117.427 millones de pesetas (INE, 1998, p. 21). 
para dar a conocer los nuevos productos y aumentar las exportaciones, por la fuerte competencia en el sector y con otros sectores próximos y alternativos, por el crecimiento del precio de las materias primas y por la presión de los grandes distribuidores. Conviene tener presente que en la primera mitad de los noventa, las marcas blancas o de distribuidor tenían, en el sector galletero, un precio entre un 27 y $35 \%$ inferior al de las industrias productoras (Puelles et al., 1997, p. 118).

La producción galletera se ha diversificado notablemente. Un $98 \%$ son galletas dulces y un $2 \%$ saladas. Entre las primeras, y pese a sus continuos descensos salvo en momentos de crisis en los que recupera compradores, la maría acapara un 37\% del mercado en 1997 (era el 51\% una década antes), seguida de la tostada con el $17 \%$, la de relieve y sandwich con un $8 \%$ cada una, surtidos con el $6 \%$ y bizcochos, barquillos y cubiertas con un 5\% cada una. En valor, la importancia de la maría se reduce por su menor precio en relación con otras más elaboradas. Estas últimas tienden a cubrir una demanda más variada que se localiza fundamentalmente en las grandes ciudades.

Uu buen indicador de la industria galletera es el empleo que genera. Sin disponer de cifras totales, conviene tener presente que predominan las empresas pequeñas y medianas. Si consideramos grandes, siguiendo los criterios oficiales españoles y de la Unión Europea (Méndez, R., y Caravaca, I., 1996, p. 39), las que superen los 250 empleados, sólo «Nabisco», «Cuétara», «Siro» y «General Biscuits» se podrían incluir en este bloque al contar con 1.085, 575, 640 y 372 empleados fijos respectivamente en 1997. Otra decena de industrias galleteras pueden calificarse como medianas (entre 51 y 250 empleos), aproximándose «Gullón» (con 225) al grupo de las grandes. El resto no llegan a los 50 empleados y serían, por tanto, catalogadas como pequeñas, según este criterio.

Sin embargo, estas cifras hay que tomarlas con precaución, ya que normalmente suelen hacer mención sólo a empleos fijos. Por ejemplo, «Nabisco» suma 180 eventuales a los 1.085 fijos y «Cuétara» tiene 360 eventuales y 575 fijos. En las empresas más pequeñas, la situación es similar: «La Flor Burgalesa» ocupa a 35 fijos y 40 eventuales y «Neules Oliveras» a seis fijos y 39 eventuales en 1997.

Otro indicador es el valor de las ventas. En 1997, «Nabisco» alcanzó los 39.376 millones de pesetas, «Cuétara» los 22.726, «Siro» los 16.200, «General Biscuits» los 11.358. «Gullón», los 11.100 y, la sexta empresa, «Industrias Rodríguez», se quedó en 3.332. Esto nos indicaría que las cin- 
co primeras tienen unas ventas muy elevadas frente al resto. Sin embargo, también estas cifras pueden ser engañosas, ya que en unos casos («Cuétara» $\mathrm{y}$ «Gullón») se incluyen sólo los ingresos por venta de galletas y en el resto se le suman los de otros sectores por ser empresas más diversificadas.

Más representativa puede ser la cuota de mercado. En el sector galletero, las cinco mayores de entonces («Cuétara», «Royal Brands», «Fontaneda», «General Biscuits» $\mathrm{y}$ «Siro») acaparaban el 61,5\% en 1993. Tras los posteriores procesos de fusiones, las cinco mayores («Nabisco», «Cuétara», «Siro», «Gullón» y «General Biscuits») acaparaban aproximadamente el $75 \%$ de las ventas en 1997. A este porcentaje hay que sumar otro $16 \%$ de las marcas blancas o de distribuidor, en constante y rápido crecimiento, ya que había sido el $12 \%$ en 1996. Este crecimiento de las marcas blancas en todos los sectores agroindustriales se explican muy fácilmente si tenemos en cuenta que «las 250 primeras empresas de la distribución en España en 1995, facturaron en conjunto cerca de seis billones de pesetas, de los que prácticamente el $45 \%$ fueron realizados por los cinco primeros grupos» (Ministerio de Economía y Hacienda, 1997, p. 125). Estas cifras permiten a «Pryca», «Continente», «Eroski», «Alcampo» e «Hipercor» negociar en una posición privilegiada con los productores, incluso aunque éstos sean multinacionales del peso de «Nestlé», «Danone» 0 «Nabisco».

Estas cifras nos indican una elevada concentración en el sector, inferior a la apuntada para los cereales de desayuno pero superior a la existente en otros productos que compiten con ambos como la pastelería industrial, en la que los cinco grandes grupos controlan un $60 \%$ de las ventas, mientras el resto está muy atomizado en pequeñas empresas de ámbito local o comarcal. Esta concentración se ha llevado a cabo por las adquisiciones de la multinacional «Nabisco» pero también por la revitalización de empresas españolas como «Cuétara», «Siro» y «Gullón», revitalización que se ha producido pese a la fuerte competencia de multinacionales e incluso comprando sus filiales como ha hecho «Siro».

\section{Principales empresas del sector galletero español}

Como han apuntado Méndez y Caravaca, «Todo intento de explicar la evolución y funcionamiento de la actividad industrial, así como sus di- 
versas formas de relación con el espacio geográfico, debe tomar en consideración el protagonismo de la empresa como agente económico esencial en las economías capitalistas» (Méndez, R., y Caravaca, I., 1996, p. 35). La empresa industrial es la unidad básica de producción y cuenta con personalidad jurídica propia que le permite decidir, gestionar y administrar desde su sede social, que no siempre coincide con la ubicación territorial de sus fábricas. A continuación repasamos la situación reciente de las principales empresas galleteras que abastecen al mercado español.

Nabisco. Fue fundada en 1898 en Estados Unidos y es la multinacional más importante del mundo en el sector galletero al controlar una parte importante de los mercados europeos y americanos. Ocupa el primer puesto en el mercado español en ventas, valor de las mismas y empleo. Se introdujo a través de sus filiales «Artiach» (fundada a fines del XIX y comprada por «Nabisco» entre 1974 y 1982) y «Marbú» (fundada en los años cincuenta y adquirida por la multinacional en 1985), pero su expansión se da fundamentalmente en los años noventa con la compra de varias grandes empresas.

En 1993 compra el 50\% de «Loste» y la comparte con «Royal Brands», absorbiendo a esta última en 1996 tras comprar las acciones de Tabacalera. Con ello consigue acercarse al $20 \%$ de la cuota de mercado, cerrar algunas fábricas y aumentar la producción de otras, creando un mercado común con otros países europeos, de Oriente Medio y norte de África.

$\mathrm{Su}$ expansión adquiere una mayor importancia cuando en agosto de 1996 compra, a través de su filial «Marbú», a la familia Fontaneda el $100 \%$ de «Galletas Fontaneda» por más de 4.500 millones de pesetas ${ }^{3}$. Esta compra le permitió a «Nabisco» aumentar su cuota en el mercado galletero español hasta casi el $30 \%$ / en ventas y valor, dejando de producir marcas blancas. La reestructuración de «Fontaneda» supuso regulación de empleo para más de 150 trabajadores, congelación salarial y fuertes inversiones en modernizar instalaciones y publicidad.

«Fontaneda» había sido fundada en 1891 por Eugenio Fontaneda en Aguilar de Campoo como confitería que vendía galletas hechas en un

3 Se excluyó de esta venta el edificio industrial de la localidad toledana de Seseña en la que Fontaneda iba a poner en marcha otra fábrica pero que nunca entró en funcionamiento. 
horno de leña y bizcochos amasados a mano. Se mantiene como empresa familiar hasta 1996, figurando durante décadas entre las primeras productoras españolas desde que lanza al mercado María en 1916. A comienzos de los noventa empleaba a unas 600 personas, la mayoría en Aguilar de Campoo, en cuya factoría producía unas 200 toneladas diarias de una veintena de variedades de galletas, que destinaba al mercado español y a exportar a unos quince países. En 1995 realiza una reestructuración productiva y comercial para reducir stocks, regulando empleo rotativo durante un mes, elimina las delegaciones comerciales y las sustituye por distribuidores pero cierra el ejercicio con pérdidas.

«Nabisco» dispone de la fábrica de «Fontaneda» en Aguilar de Campoo, la de «Marbú» en Viana (Navarra) y las de «Artiach» en Montornés del Vallés (Barcelona) y Orozko (Vizcaya) en las que elabora galletas con las marcas «Artiach», «Articoco», «Artinata», «Chiquilín», «Filipinos», «Loste», «Riera Marsá», «Marbú», etc. Su presencia en el sector agroalimentario español es amplia: fabrica los zumos «Fruco», los flanes «Royal», las conservas «Apis» (estas últimas con tres fábricas en la provincia de Badajoz), etc.

Cuétara. Fundada por emigrantes españoles en Méjico en 1935, posteriormente abre una factoría en Veracruz y, tras el regreso, en 1938, en Reinosa. En 1951, Juan y Florencio Gómez-Cuétara fundan en Reinosa la moderna factoría Gómez-Guétara Hermanos, que en 1964 se transforma en sociedad anónima, se separa de su homónima mejicana y pasa a ser «Cuétara, S. A.» (AA. VV., 1987, p. 221). Entre 1955 y 1968 crea mil puestos de trabajo e instala fábricas en Jaén, Museros, Dos Hermanas, Granollers, El Palmar, Santiago y Torrejón de Ardoz. A principios de los setenta inicia la reconversión, transformando en almacenes las instalaciones de Granollers, Dos Hermanas, El Palmar y Santiago, modernizando el resto y construyendo la de Villarejo de Salvanés, que absorbe a la de Torrejón de Ardoz, sin que el proceso afecte a los puestos de trabajo (AA.VV., 1987, p. 221).

En 1987 se amplía la fábrica de villarejo que es también la sede social. En dicho año controlaba aproximadamente un $26 \%$ del mercado español, porcentaje que superaba ampliamente en Extremadura (casi la mitad del total), Madrid, Castilla-La Mancha, Andalucía y Galicia (AA.VV., 1987, p. 197). Contaba con doce almacenes propios en Santiago, Astillero, Aizoain, Granollers, Valladolid, Utebo, Mérida, Ciudad Real, El Palmar, Granada, Dos Hermanas y Málaga, y una flota de camiones que distri- 
buían el producto en unos 24.000 puntos de venta directa, de los cuales un 63\% eran tiendas de ultramarinos (AA.VV., 1987, pp. 197-201). En 1990, su distribución se elevaba a 30.000 puntos de venta, la mitad de los establecimientos del ramo (AA.VV., 1990, p. 161).

En 1990, sus fábricas ocupaban una superficie de 70.000 metros cuadrados, con modernas instalaciones que fabricaban diariamente más de 250.000 kilos de galletas, bizcochos, barquillos, etc., hasta llegar a 40 productos diferentes en más de 100 presentaciones distintas (AA.VV., 1990, p. 159). Ocupaba a más de 1.000 trabajadores, cifra que ha ido retrocediendo hasta los 900 en 1994, 600 en 1005 y 575 en 1997. Este retroceso se da fundamentalmente en el empleo fijo, sustituido parcialmente por empleos eventuales. Este cambio va acompañado de un estancamiento de las ventas en los últimos años, alcanzando los 22.726 millones de pesetas en 1997.

En los años ochenta y noventa ha figurado habitualmente entre las cien mayores agroindustrias españolas y ha sido la segunda galletera en ventas, inversiones, empleo y exportaciones. A mediados de los noventa controlaba un $18 \%$ del mercado español ${ }^{4}$ y era líder en Portugal a través de su filial Bolachas de Portugal (Bogal) que acaparaba el 22\% de dicho mercado. Un 7\% lo destina a la exportación, que se multiplicó por diez entre 1988 y 1994 (Mate, 1995a, p. 4), vendiendo en unos 35 países de los cinco continentes a través de operadores comerciales o filiales de distribución.

Sus accionistas mayoritarios siguen siendo los Gómez-Cuétara, aunque en los noventa se ha especulado con la posible venta de parte de sus acciones, aspecto que se explica porque los dos fundadores tuvieron una veintena de hijos y los descendientes-herederos en la tercera generación superan el centenar, lo que dificulta posibles acuerdos, aunque el problema se solucionó parcialmente en 1995 cuando acuerdan repartir un tercio de los beneficios anuales y reinvertir los dos tercios restantes. En 1992 compró «Pastas San Antonio» y participa también en el accionariado de «Harinera de Belmonte, S. A.», «Cevecasa», «Cevevisa», «Gestora Alimentaria» y «Difesa». Los Gómez-Cuétara son también accionistas mayoritarios de «Solsona de Productos Alimenticios», con factoría en Daganzo (Madrid) que elabora galletas y panes especiales y que, a su

\footnotetext{
${ }^{4}$ En todas las regiones superaba el 15\%, llegando a un máximo del 30\% en Castilla-La Mancha. Si se añaden los productos vendidos como marcas blancas, Cuétara llega al 26\% de la cuota de mercado, siendo la marca líder en España (Mate, 1996, p. 7).
} 
vez, controla el 100\% de «Galletas Lar», con fábrica en Marchena (Sevilla) y el $97,7 \%$ de la zaragozana «Peipasa». Aunque su gama de productos es muy diversa, la mayor parte de sus ventas corresponden a las marcas «Cuétara», «Campurrianas», «Tosta Rica», «Delicias» $\mathrm{y}$ «Tucho».

Grupo Siro. «Galletas Siro» fue fundada en 1918 en Alar del Rey (Palencia) por Siro Fernández, iniciando su actividad con un pequeño horno artesano. Se expansiona a partir de los años setenta y en 1987 tenía una plantilla de 350 trabajadores entre sus tres fábricas: Venta de Baños, La Carolina y Getafe. Mantiene su carácter familiar hasta que en dicho año es adquirida por la multinacional francesa BSN-Danone a través de su filial «General Biscuits» que sorprendentemente, y tras cuantiosas inversiones (más de 2.000 millones de pesetas de 1987 a 1.600 en 1991. Este descenso le lleva a venderla en este año a Juan Manuel González Serna, que en tres años recupera el nivel de ventas de 1987. Para ello desarrolla una estructura comercial propia, con presencia en todo el territorio español, a través de distribuciones provinciales y depósitos. Lanza al mercado hasta 14 nuevos productos, de mayor calidad y precio, como galletas bajas en colesterol, pastas de cereales y otros productos dietéticos. Con estas medidas se amplía la oferta, se diversifica y se la dota de mayor calidad (gracias a una modernización industrial), dentro de una estrategia de responder a todas las demandas del mercado. Para ello mantiene la producción de galletas en la fábrica de Venta de Baños y cierra la de La Carolina, como anteriormente había hecho con la de Getafe.

En pleno proceso de relanzamiento de «Galletas Siro», el empresario adquiere el 55\% de «Industria Castellana de Alimentación, S. A.» (ICASA), ampliando posteriormente su participación hasta el 65\% de esta empresa que tiene fábrica en Toro en la que elabora galletas de pastas de té de la marca «Reglero». Esta incorporación permite al Grupo Siro elevar su facturación unos 1.500 millones de pesetas y diversificar su gama de productos, básicamente pastas y galletas de chocolate.

En 1994 compra la firma valenciana «Río Productos Alimenticios» a la multinacional italiana «Barilla», quedándose ésta con la propiedad de las marcas de pastas «Barilla», «Gloria» $\mathrm{y}$ «Río» y la de galletas «Molino Blanco».

Siguiendo este proceso expansivo, en 1995 compra a la multinacional «United Biscuits» el grupo de empresas «KP Larios» que incluía «KP Larios», «Dora Carreño», «Aperitivos Medina» $\mathrm{y}$ «Rosdor» y aca- 
paraba un 6,5\% de la cuota del mercado español de aperitivos. Con la incorporación de estas empresas se apuesta firmemente por la diversificación y por entrar en un sector, como el de aperitivos, con un crecimiento y valor añadido superior al de las galletas, aunque cuenta con un fuerte problema propiciado por el control de más del $50 \%$ de la cuota de mercado por «Matutano», filial de la multinacional «Pepsico» (Maté, 1995b, p. 11).

La gestión y administración del grupo se hace desde Venta de Baños ${ }^{5}$, donde está la fábrica de galletas, se mantiene la de Toro para los productos «Reglero«, la de Río en Paterna se dedica a producir galletas saladas y dulces y pastas, la de «Dora Carreño» en Alhama de Murcia se destina a la producción de snacks, patatas fritas y colines, y «Aperitivos Medinas», con fábrica en Móstoles, está especializada en frutos secos y snacks. Esta última la revendió en abril de 1998 a sus primeros propietarios, la familia Medina de la Fuente, reduciendo su presencia en este mercado aunque lo compensó creando, en 1997, «Snacks» de Castilla y León, con una inversión de 700 millones de pesetas en una nueva fábrica en el polígono industrial de Venta de Baños para fabricar patatas fritas y aperitivos para la zona norte y centro de España, con lo que abarata costes de transporte. Participa en esta empresa con un $65 \%$ del accionariado, perteneciendo el 35\% restante a «Fundosa» (de la ONCE) (Castilla y León económica, 16, 1997, p. 10).

En enero de 1998 compra la mayoría de las acciones (92,6\%) de «Productos Alimenticios La Familia« a «BSN-Danone». Esta empresa cuenta con fábricas en Tordesillas y San Cugat que elaboran pastas con las marcas «La Familia» y«Ardilla» que, sumadas a las que ya tenía («Río« y «El Sol de Oro»), le permiten controlar un 20\% del mercado de pastas, en el que se convierte en la segunda empresa en ventas tras «Gallo».

Desde septiembre de 1994, el Grupo Siro también distribuye en exclusiva para toda España los productos de la alemana Wolf, una de las empresas líder en el mercado europeo de snacks y galletas saladas.

Esta expansión empresarial y diversificación productiva ha permitido al Grupo Siro ampliar enormemente su volumen de negocio, pasando de 1.600 millones de pesetas en 1991 a unos 16.200 en 1997. En este perío-

${ }^{5}$ Desde 1995, Siro realiza la facturación de todos los productos comercializados, mientras el resto de empresas operan desde entonces como unidades fabriles. 
do también multiplica por seis sus exportaciones, centradas en Estados Unidos, Canadá y Este de Europa. Pasa a ser el tercer grupo galletero español, el segundo en pastas y patatas fritas y el cuarto en snacks y frutos secos. También incrementa notablemente los empleos generados: en 1993 ocupaban en 1912 entre «Siro» «Río», ascendiendo los del grupo a 478 en 1995 y 640 en 1997, un 95\% de estos últimos ocupados por mujeres (Castilla y León económica, 27, 1998, p. 10).

Su estrategia se basa en tres ejes: mayor calidad con mejora del proceso productivo y de los recursos humanos, nuevos productos con mayor valor añadido y ampliación del volumen de ventas para estar presente en todas las zonas de gran consumo y en los grandes canales de distribución (distribuyen sus productos en más de 6.000 puntos de venta en toda España). Según González Serna, presidente del grupo, el secreto para esta expansión es «la concentración de recursos y esfuerzos para poder aplicar economía de escala, reduciendo así los costes. Se trata, en general, de productos con un valor añadido muy bajo y el control del gasto es imprescindible». Estos principios le han servido para crear un holding agroindustrial sólido y diversificado tras comprar casi siempre empresas a multinacionales que habían fracasado con las mismas. Su propietario ha apostado por comprar a las multinacionales porque, aunque tengan problemas con alguna factoría, siempre tienen instalaciones con buena tecnología (las modernizan cuando las compran en los ochenta o principios de los noventa) y tienen cumplidas sus obligaciones fiscales.

Gullón. Fundada en 1892, durante el reinado de Alfonso XIII fue suministrador oficial de la Casa Real, teniendo una expansión considerable desde los años cincuenta. Fue la primera que inició las exportaciones hacia 1960 y la primera en fabricar galletas integrales en los ochenta, década en la que moderniza las instalaciones de la fábrica de Aguilar de Campoo. En los noventa empieza a producir galletas con aceite de oliva, liderando el mercado español de galletas dietéticas. Sigue siendo una empresa familiar al pertenecer exclusivamente a la familia Gullón.

En 1993 compra en subasta las instalaciones de Galletas Tas, también en Aguilar, iniciando las reformas en esta planta de casi 6.000 metros cuadrados que le permiten producir unos 50.000 kilos diarios desde que reinicia la actividad a comienzos de 1995 tras invertir casi $1.000 \mathrm{mi}-$ llones de pesetas en esta segunda fábrica. En 1996 compra la maquinaria y absorbe parte de la plantilla de Fontibre, también en Aguilar y en 
quiebra desde 1994, llegando a las 65.000 toneladas anuales. En ese mismo año compra «Alimentos del Noroeste, S. A.» (Alinosa) con fábrica de galletas en Orense y en 1997 adquiere la burgalesa «Galletas de Arlanzón», con lo que su capacidad de produc ción ronda las 70.000 toneladas anuales. Estas compras implican que pase de 200 empleados en 1994 a 250 en 1997, incremento muy inferior al de sus ventas: 5.650 millones de pesetas en 1992 y 11.100 en 1997, cifras que le permiten convertirse en la cuarta empresa del sector en España con una cuota de mercado del $11,5 \%$ aproximadamente.

En 1997 y 1998 realiza importantes inversiones para conquistar mercados exteriores, en los que ya comercializa sus productos en un total de una treintena de países de los cinco continentes, aunque sus exportaciones sean sólo del 5-8\% de su producción, cifra similar a la que produce para marcas bancas. Las exportaciones trata de orientarlas hacia el mercado europeo por lo que tiende a diversificar su producción para hacer frente a una demanda de galletas más elaboradas. El hecho de ser la primera galletera española en obtener el ISO 9.002 en febrero de 1997 puede abrirle algunos mercados.

General Biscuits España. A lo largo de los años noventa ha figurado entre los cinco primeros puestos del ranking de empresas galleteras aunque con variaciones por la frecuente participación en compraventa de distintas empresas. Gran parte de sus ventas son de pan y pastelería industrial, sector en el que es la segunda empresa tras el grupo «Panrico-Donut». Dispone de fábricas de pan en La Roca (Barcelona) y de galletas en Granollers, elaborando en esta última las marcas «Lu», «Dinosaurus», «Príncipe de Beuklaer», «Yayitas», etc. Pertenece al grupo Danone.

Otras empresas galleteras. Se reparten cuotas mucho más reducidas de mercado, centrándose fundamentalmente en ámbitos locales y regionales.

En Castilla y León tienen peso específico diveras empresas: «Angulo» en Lerma, «Coral» en Miranda de Ebro, «Huerta» y «La Flor Burgalesa» en Burgos, «La Sociedad Europea de Galletas» en Ávila y «Tejedor» en Soria. Sumadas a las fábricas en la zona de los grandes grupos convierten a esta autonomía en la gran productora española de galletas al superar el 50\%/ de la producción nacional.

También es significativa la producción en Cataluña: «Pujol», «Camprodon», «Cal Enric» $\mathrm{y}$ «Trías» en la provincia de Girona; «Sosa», «Ba- 
rilla» $\mathrm{y}$ «Neules Oliveras» en la de Barcelona; «Yurit» en Tarragona y «Rodríguez y Casañe» en Lleida.

La provincia de Zaragoza con las factorías de «Asinez», «Cargallo», «Juma», «Polen» $\mathrm{y}$ «Lar» tiene también una notable presencia en el sector. Mucho menor es la importancia galletera de otras provincias: fábricas de «Arluy» $\mathrm{y}$ «Reyga» en Logroño, «Bandama» en Las Palmas, «Quely» en Baleares o «Solsona» en Madrid.

La mayoría de estas empresas tienen un accionariado casi exclusivamente familiar, ya que el 100\% de «Sosa», «Angulo», «Tejedor», «Rodríguez», «Quely», «Trías», etc., pertenece a miembros de una familia. Este porcentaje se reduce ligeramente en otras empresas como «Camprodón», mientras tiende a convertirse en marginal en aquellas empresas en las que entra en el accionariado alguna multinacional. Es el caso de la familia Pujol Planella que reduce sus acciones del 20 al 5\% de «Galletas Pujol» entre 1993 y 1996, incrementándolas del 80 al 95\% la empresa francesa «Biscuiterie, filial de «Andros».

Casi todas suelen tener una menor gama de productos: «Angulo» está especializado en bizcochos (que suponen un $90 \%$ de sus ventas) al igual que «Coral»; las fábricas catalanas en neules; «Arluy» en galletas bañadas en chocolate; «Yurit» en barquillos; «Asinez», «Gargallo» $\mathrm{y}$ «Polen» en galletas aunque esta última se diversifica con frutas de Aragón y, por último, la granadina «Sanavi» en galletas dietéticas, de venta exclusiva en herbolarios.

Para hacerse con una cuota mayor de mercado tienen que recurrir a las marcas blancas impuestas por los distribuidores. Es el ejemplo de la abulense «Sociedad Europea de Galletas» que, pese a distribuir galletas y chocolates con una marca conocida (Elgorriaga) tiene que comercializar un 55\% de su producción en 1997 con marcas blancas, lo que reduce notablemente sus beneficios. Esto, unido a su escasa diversificación y cuota de mercado, hace que sus inversiones hayan sido reducidas en la última década en la que «Asinez» $\mathrm{y}$ «La Flor Burgalesa» han puesto en marcha nuevas instalaciones y «Arly» las ha ampliado al tiempo que renovaba la maquinaria para automatizar parte del proceso productivo.

\section{Capital extranjero}

La presencia de capital extranjero en la agroindustria española es bastante antigua y un buen ejemplo es la fábrica de «Nestlé» en la lo- 
calidad cántabra de La Penilla, que data de 1905. El decreto-ley de 27 de julio de 1959 concedía libertad absoluta para aquellas inversiones inferiores al 50\% del capital suscrito por las sociedades y establecía, para las superiores, la necesidad de obtener una autorización administrativa. En abril de 1963 se suprime la necesidad de autorización previa del Consejo de Ministros para rebasar el 50\% del capital para las inversiones extranjeras en distintas industrias, entre ellas las agroalimentarias y las de alimentación del ganado. Esta mayor facilidad a la inversión exterior supuso indirectamente una mayor dificultad para conocer el grado de penetración del capital extranjero en el sector (Feo Parrondo, 1988-89, pp. 127-128).

Desde los años sesenta, se incrementa paulatinamente la presencia de capital extranjero en el sector galletero español y así, en 1987, las cuatro grandes multinacionales del sector competían en el mercado español: la norteamericana «Nabisco» a través de «Artiach» $\mathrm{y}$ «Marbú», la inglesa «United Biscuits» con «Ortiz», la alemana «Bahlsen» por medio de «Loste», y la francesa «General Biscuit» a través de «Gebeco Lu» (AA.VV., 1987, p. 137). Sin embargo, «su participación en el mercado galletero ha venido siendo minoritaria, no habiendo conseguido avances notables, dada la competitividad de las primeras marcas originarias españolas, cuyas calidades, precio y servicio, siguen mereciendo hoy en día las preferencias de los clientes y consumidores nacionales» (AA.VV., 1987, p. 137). Esta competitividad se debía a que en el sector «ha habido una concentración y mejora considerable de las estructuras técnicas y económicas al amparo del aumento de consumo, apareciendo algunas empresas de nivel europeo («Fontaneda», «Cuétara», «Siro») (Feo Parrondo, 1988-89, p. 115).

A lo largo de la década de los noventa, la situación ha cambiado significativamente. La entrada en la Unión Europea y la globalización han colaborado para que en el sector se hayan producido cambios importantes y constantes en la presencia de capital extranjero. En esta globalización han jugado un papel decisivo las nuevas tecnologías, la eliminación de barreras al comercio y al desarrollo de negocios internacionales, la desaparición de los sistemas de planificación centralizada, etc. Sin embargo, «el rasgo esencial que diferencia esta etapa de las precedentes es la generalización progresiva de una lógica mundializada que orienta la actuación de cada vez más empresas e instituciones a la hora de delimitar sus mercados, buscar sus proveedores, di- 
rigir sus inversiones o localizar sus establecimientos. De este modo, tanto la producción, como la circulación y la distribución se organizan a esa escala, al tiempo que los espacios nacionales pierden parte de su importancia como elemento clave para la acumulación de capital» (Méndez, 1997, p. 108). Esta globalización tiende a darse también en el consumo por la difusión de modelos de comportamiento a través de la publicidad de las grandes empresas.

«Nabisco», tras adquirir «Loste», absorbe «Royal Brands» y compra «Fontaneda» entre 1993 y 1996, se ha convertido en la primera empresa vendedora de galletas en España, siendo también la líder en el mercado mundial del sector.

El resto de las multinacionales tienen un peso mucho más reducido en el sector galletero español. Algunas de las principales a finales de los ochenta y primera mitad de los noventa, como «General Biscuits España», 100\% del grupo BSN-Danone, ha ido vendiendo parte de sus empresas como consecuencia de su fracaso económico como hemos apuntado anteriormente, lo que no le impide seguir figurando entre las cinco primeras del sector ${ }^{6}$. También la italiana «Barilla» vende en 1994 la galletera «Río» al Grupo Siro y deja su marca «Mulino Bianco» en manos de la comercial Cide en 1995, quedándose reducida su producción a la de pastas en su fábrica zaragozana. Por el contrario, «Biscuiterie Baie du Mont S. Michel, S. A., también francesa y filial de «Andros», ha ampliado su participación en el accionariado de Pujol desde el 80 al 95\% entre 1993 y 1995, teniendo un peso significativo en el mercado catalán. Por último, solamente la «Sociedad Europea de Galletas», con factoría en Ávila, tiene el $100 \%$ de su capital extranjero, perteneciente al grupo francés Cantalou.

\section{Cambios en el consumo}

La evolución del sector galletero español se explica más fácilmente si tenemos en cuenta la evolución de la demanda. El consumo medio per cápita se incrementa lenta pero constantemente entre 1960 y 1990: 1,60 kilos en 1961, 2,61 en 1965, 3,88 en 1970, 4,48 en 1975, 4,94 en 1980 y 5,2

${ }^{6}$ El grupo Danone, es uno de los mayores holdings agroindustriales del mundo. En el sector galletero, controla las mayores empresas de tres de los países con mayor expansión de la demanda: Rusia, Brasil y Argentina. 
en 1990 (AA.VV., 1987, p. 181, y AA.VV., 1990, p. 143). Este aumento no impide que el consumo de galletas en España esté bastante por debajo del de otros países europeos: en 1983 no llegaba a los cinco kilos per cápita en España frente a los 14 de Holanda, 12,8 de Gran Bretaña, 10,8 de Irlanda, 9,6 de Francia, 9,4 de Bélgica y Luxemburgo y 8,7 de Dinamarca (AA.VV., 1987, p. 183).

El mercado galletero español ha tardado bastante en diversificarse. En 1987, la galleta «maría» acapraba el $51 \%$ del mercado interior y de las ventas seguida de la tostada con un $17-18 \%$ y de los barquillos con un $6 \%$ (AA.VV., 1987, pp. 186). En 1990, las marías suponían todavía casi el 50\%, seguidas de las tostadas con el $22 \%$, barquillos con el $5,32 \%$ y surtidos con el 5,15\% (AA.VV., 1990, p. 152).

Lamentablemente, los estudios publicados por el MAPA sobre consumo alimentario o alimentación, no precisan adecuadamente las cifras del consumo galletero de los españoles en la década de los noventa al agrupar en un mismo lote las galletas, bollería y pastelería, disprando al alza los datos anteriores. La demanda de galletas, bollería y pastelería se eleva notablemente en España desde los 12,5 kilos per cápita en 1987 (de ellos unos cinco de galletas) hasta llegar a un máximo de 15,2 kilos/habitante en 1991 para reducirse luego paulatinamente hasta los 12 en 1997. El peso de los productos vendidos pasó de 485 millones de kilos en 1987 a 600 en 1991 y 466,8 en 1995. Una evolución similar ha tenido el valor de dichas ventas: 163.411 millones de pesetas en 1987, 281.428 en 1991 (maximo) y 231.288 en 1995. Únicamente en su estudio de 1998 desglosa el MAPA las cifras de producción de galletas, pastelería industrial y cereales para el desayuno. Cifra la producción de pastelería industrial en 216.000 toneladas, la de cereales de desayuno en 30.000 y la de galletas en 270.000 toneladas. Sin embargo, el valor es mayor en la primera (96.000 millones de pesetas) frente a los 72.000 del subsector galletero.

A lo largo de la primera mitad de los noventa se ha reducido considerable y sorprendentemente el número de familias que compran estos productos: $89 \%$ en 1990 y sólo un $81,7 \%$ en 1995 . Este descenso puede explicarse por una menor demanda ante cambios en la dieta. Según los datos del MAPA, el consumo es mayor en zonas urbanas, en familias reducidas y de estatus alto y en las que el ama de casa tiene más de sesenta años. Con ligeras oscilaciones anuales, un $88-90 \%$ se suelen consumir en el hogar, un 8-10\% en hostelería y restaurantes y un 2-3\% en instituciones. Mientras en bollería y pastelería tiende a aumentar el 
consumo extradoméstico, en galletas se mantiene estable el doméstico por su mejor conservación. Esto hace que tienda a descender su importancia en los gastos de los hogares (3,5\% del total en 1995) y a aumentar ligeramente el producido en hostelería $(1,1 \%)$ e instituciones (2,45 en 1995) (MAPA, 1996, pp. 61-63), situación que es general para la práctica totalidad de los productos, especialmente en zonas urbanas, entre matrimonios jóvenes, familias reducidas, en las que la mujer trabaja fuera del hogar, etc.

Asimismo, se han producido cambios muy sustanciales en el lugar de compras de galletas, bollería y pastelería: entre 1990 y 1995, la cantidad comprada en tiendas tradicionales ha pasado del 50 al 30,8\%, la de supermercados y autoservicios sube del 37,1 al 39,9\%, la de los hipermercados pasa del 8,3 al $21,1 \%$, la de economatos y cooperativas se incrementa del 1,6 al 1,9\%, la de los mercadillos callejeros sube del 1 al 1,2\% y la de otros lugares de compras del 1,7 al 4,8\% (MAPA, 1996, p. 123). Como en otros productos, los hipermercados han incrementado notablemente su cuota de mercado a costa de las tiendas tradicionales.

También se han producido algunas variaciones territoriales en este consumo. En 1987, la mayor demanda de galletas de daba en Cantabria, Rioja, Castilla-León, Castilla-la Mancha, País Vasco y Baleares, siendo las provincias con un mayor consumo per cápita las de Segovia, Ciudad Real y Burgos. Los mínimos se daban en Andalucía (especialmente en Sevilla, Huelva y Cádiz), Valencia y Canarias (AA.VV., 1987, pp. 124-125). En los noventa, Castilla-León, Madrid y Castilla-La Mancha generan la mayor demanda y Canarias la menor. Tiende a aumentar el consumo en Andalucía y Valencia y a disminuir en Galicia y Asturias.

\section{Comercio exterior}

Tradicionalmente, la producción galletera española se destinaba al mercado interior aunque «Gullón» inicia las exportaciones hacia 1960, que luego continúan otras empresas y en 1987 exportábamos a Francia, Italia, Suiza, Suecia, Canadá, Estados Unidos, diversos países hispanoamericanos, Marruecos y algunos asiáticos (AA.VV., 1987, p. 161).

Aunque las cifras no son muy fiables, a principios de los noventa las importaciones doblaban a las exportaciones, situación que se invierte a 
lo largo de esta década: en 1990 exportábamos 4.278 toneladas y en 1997 la cifra se había elevado a 56.931 toneladas, el $21 \%$ de las galletas producidas en España. Mientras las exportaciones casi se multiplicaron por trece entre 1990 y 1997, las importaciones lo hicieron por 2,6, pasando de unas 13.000 a 34.861 toneladas en dicho período. Sin embargo, el incremento en valor de las importaciones es mayor por ser productos de alta calidad.

Este incremento de las exportaciones se debe al estancamiento en el consumo interno anteriormente apuntado y al descenso de los márgenes de beneficios en el mercado español ante las presiones de los grandes grupos distribuidores ${ }^{7}$ que fuerzan a las empresas galleteras a buscar nuevos mercados.

Este proceso se ve favorecido por la larga duración del producto (unos dieciocho meses), por la buena aceptación de las «marías» en países del Este de Europa, Magreb y Latinoamérica, que adquieren un alimento completo y de calidad a un precio accesible (en una situación de muchos países semejante a la española de las décadas posteriores a la guerra civil) y por la escasa competencia en este segmento del mercado de países como Francia, Gran Bretaña o Alemania, centrados en la fabricación y exportación de productos más sofisticados.

También ha jugado un papel decisivo en el incremento de las exportaciones la concentración empresarial del sector, ya que sólo las grandes empresas pueden hacer frente a los gastos de abrir nuevos mercados exteriores por la vía de crear filiales o realizar grandes inversiones en publicidad. De hecho, en la segunda mitad de los noventa y con las lógicas diferencias interanuales, los cuatro grandes grupos («Nabisco», «Cuétara», «Siro»y «Gullón») controlan aproximadamente el $95 \%$ de las exportaciones españolas de galletas. El resto lo vende un número reducido de empresas («Arly», «Repostería Martínez», etc.) que tratan de crecer en mercados expansivos, pero muy inestables, del este europeo, mundo islámico y Brasil, aunque Portugal es el principal comprador de las galletas exportadas desde España.

\footnotetext{
${ }^{7}$ Aunque es difícil precisar la importancia de este descenso de beneficios, algunos empresarios lo cifran en un $60 \%$ a lo largo de la última década, cifra que se explica por el menor precio de las marchas blancas, los pagos aplazados a tres meses desde que se les sirve el producto, etc.
} 


\section{BIBLIOGRAFÍA}

AA.VV. (1987): Las galletas, Madrid, Cuétara, 300 pp.

AA.VV. (1990): Las galletas, Madrid, Cuétara, 277 pp.

ALIMARKET (1992-1998): Informe anual (...). Alimentación no perecedera, Madrid (un volumen cada año).

Bustos GISBERT, M. L. (1994): «La industria agroalimentaria en España», Estudios Geográficos, 215, pp. 229-256.

Castilla y León económica, . $^{\circ} 1$ (junio 1996), a 31 (diciembre 1998).

CASTRO, S. (1997) «Las exportaciones hacen despegar el sector galletero español», Super Aral Lineal, 1361, pp. 32-36.

Escorinuela, P. (1996): «Un desayuno de 20.000 millones. Kellogg, Nestlé y Pacual copan el mercado español de cereales», El PaísNegocios, 25 agosto, p. 6.

Feo PARRondo, F. (1988-89): «La industria agroalimentaria en España», Boletín de la Real Sociedad Geográfica, 114-115, pp. 105-129.

- (1991): «La agroindustria: un tema marginado en la Geografía española», en Actas del VI Coloquio de Geografía Rural, Madrid, AGE-UAM, pp. 21-30.

- (1994): «La industria en Aranda de Duero: planificación, multinacionales y desarrollo endógeno» en La industria en la planificación urbana, Girona, Universidad-AGE, pp. 173-182.

- (1997a): "Agroindustria y comercialización de productos agropecuarios», Geographicalia, 34, pp. 111-135.

- (1997b): «Industrias lácteas en España: Central Lechera Asturiana», Estudios Geográficos, 229, pp. 565-591.

GARCÍA RAMÓN, M. D. (1992): «Desarrollo y tendencias actuales de la geografía rural (1980-1990). Una perspectiva internaciona y una agenda para el futuro», VI Coloquio de Geografía Rural. Ponencias, Madrid, AGE-UAM, pp. 13-35.

GIANOLA, G. (1973): La industria moderna de galletas y pastelería, Madrid, Paraninfo, 270 pp.

Gómez Damborenea, P. (1996): «Galletas con nombre propio», El País Negocios, 18 agosto, p. 5.

HERRERo PRIETO, L. C. (1990): Aproximación a la economía palentina: análisis del sector industrial y su evolución reciente, Palencia, Ayuntamiento, 83 pp.

INC (Inst. Nac. Consumo) (1982): Información básica al consumidor sobre el Código Alimentario Español. Galletas, Madrid, INC., 24 pp.

INE (1997): Encuesta industrial de empresas, Madrid.

- (1998): Encuesta industrial de productos 1998, Madrid, $345 \mathrm{pp}$.

JUNTA DE CASTILLA Y LEÓN (1990): Directorio de industrias agrarias y alimentarias de Castilla y León, Valladolid, $316 \mathrm{pp}$.

LABRADOR, A. (1987): «Un negocio crujiente. Tres multinacionales se reparten el mercado de cereales de desayuno", El País Negocios, 22 noviembre, p. 5.

LIBERAL, J. (1994): «Galletas Siro invierte 750 millones», Super Aral Lineal, 1212, pp. 32-33.

- (1995): «Gullón opta a los primeros puestos», Super Aral Lineal, 1231, pp. 32-33.

LORENZO, J. L. (1997): «Capital extranjero en la industria alimentaria: el caso Fontaneda», en Anuario de Castilla y León, 1997, Valladolid, Ámbito, pp. 180-181.

MANERo, F. (1983): La industria en Castilla y León (dinámica, caracteres e impacto), Valladolid, Ámbito, 238 pp.

MAPA (1991): El consumo alimentario en España, Madrid, t. 1, pp. 659-677.

(1992-1998): La alimentación en España, Madrid (un volumen cada año).

Mate, V. (1995a): «El pacto de familias consolida Galletas Cuétar», El País Negocios, 2 abril, 4 pp.

- (1995b): «El grupo galletero Siro entra en el sector de aperitivos», El País Negocios, 24 septiembre, $11 \mathrm{pp}$. 
- (1996): «Todos los Cuétara quieren vender», El País Negocios, 24 noviembre, $7 \mathrm{pp}$.

MAYA FRADES, A. (1996): «La industria agroalimentaria en León: un sector emergente», en LÓPEZ TRIGAL, L. (Coord.): La disponibilidad de recursos y el desarrollo industrial leonés, León, Universidad, 133 págs., cfr. pp. 75-103.

MÉNDEZ, R. (1997): Geografía económica. La lógica espacial del capitalismo global, Barcelona, Ariel, 384 pp.

MÉNDEZ, R., Y CARAVACA, I. (1996): Organización industrial y territorio, Madrid, Síntesis, $365 \mathrm{pp}$.

MiNISTERIO DE ECONOMÍA Y HACIENDA (1997): «Marcas de distribuidor. Especial referencia al precio», Distribución y consumo, 33, pp. 112-129.

Real ACademia Española (1992): Diccionario de la lengua española, Madrid, Espasa-Calpe, 2 vols.

WOLTER, A. (1990): Galletas, Barcelona, C. Lectores, 36 pp.

RESUMEN: La industria galletera en España. En el trabajo se estudia este subsector agroindustrial, su delimitación, evolución y situación actual, producción en cantidad y valor, empleo, principales empresas, participación del capital exterior, cambios en el consumo y comercio exterior.

Palabras Clave: Galletas, agroindustria, España.

RESUMÉ: L'industrie biscuitière en Espagne. Dans ce travail on étudie ce sous-secteur agroindustriel, sa délimitation, son évolution et sa situation actuelle, sa production en ce qui concerne la quantité et la valeur, l'emploi, principales entrepises, participation du capital extérieur, changements produits dans la consommation et le commerce internationale.

MOTS CLES: Biscuits, agroindustrie, España.

ABSTRACT. The biscuit industry in Spain. In this essay the following items are dealt with: this agroindustrial area, its limits, development and present day situation, production as refecs to quantity and value, employment, foreign capital shere, changes in consumption and foreign trade.

KEY wORDS: Biscuits, Food industry, España. 